\title{
OCHRONA ŚRODOWISKA W KULTURZE STRATEGICZNEJ NIEMIEC
}

\author{
Helena Wyligała \\ Dolnośląska Szkoła Wyższa \\ Wydział Nauk Społecznych i Dziennikarstwa \\ e-mail: helena.wyligala@dsw.edu.pl
}

\begin{abstract}
Streszczenie: Celem artykułu jest analiza roli ochrony środowiska w kulturze strategicznej Niemiec ze szczególnym uwzględnieniem ochrony klimatu. Pośrednim celem jest także włączenie zagadnień ochrony środowiska do nurtu badań uwarunkowań polityki zagranicznej i bezpieczeństwa państwa. Przypadek Niemiec jest w tej sytuacji szczególny. Państwo to nie posiada jasno określonej strategii bezpieczeństwa narodowego, jednak aspiruje do ogrywania znaczącej roli w międzynarodowej polityce bezpieczeństwa i międzynarodowych działaniach na rzecz ochrony środowiska i zmian klimatycznych. W artykule połączono wiedzę ogólną na temat ochrony środowiska i kultury strategicznej z wiedzą szczegółową na temat modeli analizy kultury strategicznej Niemiec, uwarunkowań kultury strategicznej Niemiec z uwzględnieniem ochrony środowiska, oraz poziomów analizy kultury strategicznej tego państwa.
\end{abstract}

Słowa kluczowe: ochrona środowiska, kultura strategiczna, Niemcy

\section{WSTEPP}

Celem niniejszego artykułu jest analiza roli zagadnień ekologicznych (ochrony środowiska, ochrony klimatu) w kulturze strategicznej Niemiec. Pośrednim celem jest także włączenie zagadnień ochrony środowiska do nurtu badań nad uwarunkowaniami polityki zagranicznej i bezpieczeństwa państwa. Przypadek Niemiec jest w tej sytuacji szczególny. Państwo to nie posiada jasno określonej strategii bezpieczeństwa narodowego, jednak aspiruje do ogrywania znaczącej roli w międzynarodowej polityce bezpieczeństwa i międzynarodowych działaniach na rzecz ochrony środowiska i zmian klimatycznych. Włączanie zagadnień ekologicznych do tzw. high politics ${ }^{1}$ świadczy nie tylko o nadaniu im większej

1 Ditzel P. C., Die internationale Klimapolitik aus neorealistischer Perspektive Erklärungsansätze für das Staatsverhalten von Deutschland und den USA, [w:] Casebook internationale Politik, Hrsg.: M. Müller, VS Verlag für Sozialwissenschaften, Wiesbaden 2011, s. 138-140. 
wagi politycznej, ale także sprzyja profilowaniu wizerunku Niemiec na zewnątrz. Państwo to postrzegane jest przez partnerów jako ważny sojusznik oraz gracz na arenie międzynarodowej. Istotne więc wydaje się sprawdzenie czy w kulturze strategicznej Niemiec odnaleźć można elementy świadczące o odnotowywanym od ponad dwóch dekad zaangażowaniu w projekty zapobiegania zagrożeniom wynikającym ze zmian klimatycznych. Przyjęto założenie, że Niemcy w ramach międzynarodowych norm i procesów dopiero budują swoją kulturę międzynarodowego zaangażowania w ochronę środowiska poprzez politykę bezpieczeństwa. W tym zakresie postawiono pytania szczegółowe: 1. czy dziedzina ochrony środowiska może być elementem kultury strategicznej?, 2. czy ekologizacja dyskursu politycznego ma wpływ na kulturę strategiczną w polityce zagranicznej i bezpieczeństwa?, 3. na ile trwała jest zaobserwowana tendencja? Metodologia badania oparta została na zestawieniu elementów będących podstawą czynnikowej analizy kultury strategicznej oraz poziomów analizy polityki zagranicznej państwa. Powstałe w ten sposób narzędzie analityczne wskazuje obszary, w ramach których poszukiwana będzie obecność zagadnień ochrony środowiska.

\section{OCHRONA ŚRODOWISKA W STUDIACH STRATEGICZNYCH}

Współcześnie odnotowuje się wzrost znaczenia działań na rzecz ochrony środowiska naturalnego ${ }^{2}$ jako dziedziny obejmującej żywotne kwestie zapewniania bytu narodowego. W obliczu faktu, iż klęski żywiołowe i katastrofy spowodowane działalnością człowieka stanowią poważne zagrożenie dla zdrowia i rozwoju społeczeństw, państwa podejmują działania w zakresie niwelowania tego typu niebezpieczeństw. Ważnym obszarem aktywności podmiotów działających w ramach systemu bezpieczeństwa państwa jest adaptacja do zmian, które zaszły i będą zachodzić w środowisku. Przykładowo spośród wielu warto wymienić reagowanie na okresy susz i związane z nimi niedobory wody pitnej, bądź gwałtowne opady deszczu, powodujące dotkliwe powodzie, jak to miało miejsce już w wielu miastach Europy, także w Niemczech. Dewastacja środowiska naturalnego i zachodzące w nim zmiany zarówno w wymiarze globalnym (np. zanieczyszczenie powietrza, topnienie lodowców, erozja gleb i nadmierne wycinanie lasów), jak i lokalnym (np. gwałtowne zjawiska powodziowe, skażenia, smog), są zagrożeniem jakości życia, rozwoju, a w konsekwencji także przetrwania społeczeństw. Środowisko stanowi więc fundamentalną, choć często jeszcze nie uświadomioną wartość dla polityki bezpieczeństwa państw i narodów. ${ }^{3}$

2 Ochrona środowiska rozumiana jest jako całokształt działań zmierzających do naprawienia szkód wyrządzonych zasobom naturalnym lub do zapobiegnięcia ich wyrządzeniu, obejmuje także działania zmierzające do zmniejszenia ryzyka wystąpienia takich szkód bądź zachęcające do bardziej efektywnego wykorzystywania zasobów naturalnych.

3 Pawlikowska I., Bezpieczeństwo jako cel polityki zagranicznej państwa, [w:] Wstęp do teorii polityki zagranicznej państwa, red. R. Zięba, s. 69-77. 
Zagrożenia naturalne i antropogeniczne, w tym skutki zmian klimatu, posiadają cechy tradycyjnych zagadnień dyplomatycznych, podobnie jak terroryzm czy proliferacja broni masowego rażenia. Wobec nich powinny być rozwijane różnorodne strategie działania państw (np. adaptacji, mitygacji, strategicznego planowania), skierowane zarówno na potrzeby własne, jak i potrzeby wspólnoty międzynarodowej. ${ }^{4}$ Katastrofy środowiskowe i ekstremalne zjawiska pogodowe stanowią wyzwanie dla społeczeństw, gospodarek, rządów, regionów i organizacji międzynarodowych. Od lat 70. XX wieku rozwiązania globalnych problemów środowiskowych poszukuje się nie w strategiach konfrontacyjnych, lecz kooperacyjnych $^{5}$, które w literaturze obejmującej studia strategiczne nie stanowiły dotąd istotnego obszaru badawczego. Od lat 90 . XX wieku stały się jednak przedmiotem badań w ramach environmental security studies. ${ }^{6}$

\section{KULTURA STRATEGICZNA I JEJ ŹRÓDŁA}

W 1977 r. prekursor studiów strategicznych J. Snyder wskazywał, iż kultura strategiczna jest sumą wyobrażeń i ogólnych sądów, postaw i wzorów zachowań, charakterystycznych dla członków narodowej strategicznej wspólnoty, który to zbiór osiągnął stan względnej trwałości. ${ }^{7}$ Kształtowana w toku procesów historycznych percepcja wpływa na swoiste przetwarzanie zagadnień strategicznych i odzwierciedlanie ich w decyzjach politycznych. Jest więc bardzo ważna dla uchwycenia tożsamości danego podmiotu w sprawach bezpieczeństwa i obrony. Wyjaśnienie pojęcia tożsamości może wspomóc lepsze rozumienie specyfiki danej kultury strategicznej. ${ }^{8}$ Odnosi się ono bowiem do sposobu, w jaki myślimy o sobie i w jaki konstruujemy narrację o nas, z czym identyfikujemy się emocjonalnie. ${ }^{9} \mathrm{~W}$ studiach nad kulturą rozróżniane są dwa modele postrzegania tożsamości: jako podstawowego, uniwersalnego i niezmiennego sedna własnego ja, rozpowszechnionego zwłaszcza w kulturze zachodniej oraz jako postawy, w której własne ja uwarunkowane jest konkretnym czasem i miejscem, nieoddzielone od społecznych więzi. Dla A. Giddensa tożsamość stanowi o zdolności do budowania stałego poczucia kontynuacji poprzez zdarzenia, w których poszukujemy odpowiedzi na krytyczne pytania: co

${ }^{4}$ Mitchell R. B., International Politics and the Environment, SSFIR, Sage 2010, s. 191-198.

5 Zob. szerzej: Łoś-Nowak T., Stosunki międzynarodowe. Teorie - systemy - uczestnicy, Wyd. UWr., Wrocław 2006, s. 192-196.

6 Dalby S., Zmiany w środowisku, [w:] Studia bezpieczeństwa, red. P. D. Williams, Wyd. Uniwersytetu Jagiellońskiego, Kraków 2012, s. 256-269.

7 Za: Lantis J. S., Howlett D., Kultura strategiczna, [w:] Strategia we wspótczesnym świecie. Wprowadzenie do studiów strategicznych, red.: J. Baylis, J. Wirtz, C.S. Gray, E. Cohen, Wyd. Naukowe UJ, Kraków 2009, s. 91.

8 McDonald M., Konstruktywizm, [w:] Studia bezpieczeństwa, red. P. D. Williams, Wyd. Naukowe UJ, Kraków 2012, s. 62.

9 Barker Ch., The SAGE Dictionary of Cultural Studies, SAGE Publications 2004, s. 180-181. 
robić, jak działać, kim być. Wskazuje nie na posiadane cechy, a bardziej na zwrotne (refleksyjne) rozumienie tego, co myślimy o tym, kim jesteśmy teraz - w świetle naszej przeszłości i teraźniejszości, w połączeniu z myśleniem o tym, kim chcielibyśmy być $\mathrm{w}$ przyszłości. ${ }^{10}$ Takie pojmowanie tożsamości pozwala lepiej uchwycić istotę kultury strategicznej danego podmiotu, polegającą na posiadaniu specyficznych przekonań i charakterystycznych wzorców jako fundamentów podejmowanych decyzji oraz zachowań w zakresie bezpieczeństwa. Uwzględnienie kultury w badaniu bezpieczeństwa pozwala zaakcentować fakt, że nie zawsze narodowe preferencje i interesy są obiektywnie zdeterminowane; że ich kreacja odbywa się w sposób bardziej złożony i kompleksowy, w zależności od intensywności i stopnia zróżnicowania fizycznych, politycznych oraz społeczno-kulturowych źródeł kultury strategicznej badanego społeczeństwa.

Tabela 1: Typologia źródeł kultury strategicznej

\begin{tabular}{|c|c|c|}
\hline Źródła fizyczne & Źródła polityczne & $\begin{array}{c}\text { Źródła } \\
\text { społeczno-kulturowe }\end{array}$ \\
\hline $\begin{array}{l}\text { - Położenie } \\
\text { i środowisko } \\
\text { geograficzne } \\
\text { - Klimat } \\
\text { - Bogactwa naturalne }\end{array}$ & $\begin{array}{l}\text { - Doświadczenia historyczne } \\
\text { - Przekonania i wzory zachowań elit } \\
\text { - System polityczny, struktura polityczna } \\
\text { - Organizacja wojskowości i obronności } \\
\text { - Systemy zapewniania bezpieczeństwa }\end{array}$ & $\begin{array}{l}\text { - Mity i symbole } \\
\text { - Metafory } \\
\text { - Teksty (dyskurs } \\
\text { strategiczny) }\end{array}$ \\
\hline
\end{tabular}

Źródło: zmodyfikowana i uzupełniona przez autorkę propozycja autorstwa J. S. Lantis, D. Howlett, Kultura strategiczna, [w:] Strategia we współczesnym świecie. Wprowadzenie do studiów strategicznych, red.: J. Baylis, J. Wirtz, C.S. Gray, E. Cohen, Wyd. Naukowe UJ, Kraków 2009, s. 94.

Bazując na rozważaniach J. S. Lantis i D. Howlett ${ }^{11}$ przyjęto, że strategiczne działania państw są wynikiem zależności pomiędzy uwarunkowaniami systemu międzynarodowego, interesem narodowym oraz kulturą społeczeństwa danego państwa. Kultura może być przy tym postrzegana w trojaki sposób: jako zmienna zależna służyć uzupełniająco i drugorzędnie do wyjaśniania decyzji politycznych, jako zmienna niezależna tworzyć równoważny dla innych czynników obszar odniesienia badawczego, a także być traktowana autonomicznie jako niewymierny czynnik kształtujący politykę.

Niektóre ze źródeł kultury strategicznej są niewymierne, a ich weryfikowalność jest utrudniona. Bazuje ona na historycznej obserwacji i doświadczeniu oraz wynikających z nich prawideł. W niniejszym artykule założono, że elementy składające się na kulturę strategiczną (jej źródła) mogą podlegać ewolucji, co wynika ze wspomnianych wcześniej doświadczeń historycznych, ale także zmian pokoleniowych oraz przemian charakteru środowiska międzynarodowego, np. procesów globalizacji, regionalizacji, instytucjonalizacji, itp. Ponadto

\footnotetext{
${ }^{10}$ Tamże, s. 181.

${ }^{11}$ Lantis J. S., Howlett D., dz. cytowane, s. 87-106.
} 
w ujęciu konstruktywistycznym rozumie się kulturę strategiczną jako tworzoną przez społeczeństwo siatkę norm i wzorów zachowań, obszar, w którym toczona jest debata pomiędzy reprezentantami subkultur, w tym elitami i opinią publiczną, będących nośnikami i inspiratorami dominujących wątków w praktyce politycznej. $^{12}$

Wyszczególnienie źródeł kultury strategicznej pozwala dokonać analizy jej związków z innymi obszarami funkcjonowania państwa. Odnosząc się do zaproponowanych powyżej źródeł kultury strategicznej w kontekście ochrony środowiska warto zwrócić uwagę na czynniki fizyczne determinujące postrzeganie i artykułowanie własnego interesu strategicznego. Cechy położenia geograficznego państwa mogą mieć znaczenie dla prezentowanych na forum międzynarodowym opinii, np. państwa wyspiarskie, których istnienie zagrożone jest podniesieniem się poziomu oceanów, definiują swoje interesy strategiczne w zakresie bezpieczeństwa poprzez walkę z globalnym ociepleniem. Posiadane bogactwa naturalne i ich eksploatacja mogą wywoływać nie tylko lokalne skutki, np. wzrost zamożności podmiotu, ale i ogólnoświatowe konsekwencje. W przypadku Chin eksploatacja pierwiastków ziem rzadkich stanowi przedmiot ogólnoświatowej dyskusji o charakterze strategicznym, zaś formy eksploatacji kopalin i innych zasobów naturalnych, powodujące znaczące zanieczyszczenie i przekształcenia środowiska, stają się motywem podejmowania współpracy technologicznej i innowacyjnej na rzecz poprawy tej sytuacji. W ramach czynników politycznych tradycja lub też doświadczenie zajmowania się przez państwo problematyką ochrony środowiska w przeszłości może generować działania w zakresie zmian w organizacji politycznej, jak też w systemach zapewniania bezpieczeństwa. Dobrym przykładem jest RFN, która w wyniku coraz większych interakcji międzynarodowych w zakresie ochrony środowiska oraz wskutek awarii elektrowni atomowej w Czarnobylu powołała do życia w 1986 r. nowe ministerstwo: Federalne Ministerstwo Środowiska, Ochrony Przyrody i Bezpieczeństwa Reaktorów. Aspekty społeczno-kulturowe wiążą się z zakorzenionym od wielu lat w społeczeństwie nastawieniu do spraw środowiskowych oraz formułowaniu w toku społecznej interakcji stanowisk wobec różnych zjawisk osadzanych w kontekście historycznym i społecznym. ${ }^{13}$ Generalizując, ochrona i eksploatacja zasobów przyrody, w tym utrzymanie czystego i zdrowego środowiska, są dla społeczeństw państw wysokorozwiniętych motywem do egzekwowania od władzy konkretnych działań i decyzji. Wreszcie normy międzynarodowe oraz rozwój technologii i zmiany międzygeneracyjne wymuszają na decydentach konieczność podejmowania tematyki międzynarodowej ochrony środowiska, która stając się treścią agendy najważniejszych na świecie instytucji, obliguje do zajmowania przez państwo stanowiska w danej sprawie.

${ }^{12}$ H. Biehl, B. Giegerich, Introduction, [w:] Strategic Cultures in Europe. Security and Defence Policies Across the Continent, Eds. H. Biehl, B. Giegerich, A. Jonas, Springer VS, Wiesbaden 2013, s. 12.

${ }^{13}$ McDonald M., dz. cytowane, s. 61. 


\section{MODEL ANALIZY KULTURY STRATEGICZNEJ NIEMIEC}

Wyjaśnienie założenia o obecności ochrony środowiska w kulturze strategicznej Niemiec oparte zostało na modelu zaproponowanym przez K. Longhurst. ${ }^{14} \mathrm{Wy}-$ znaczyła ona trzy podstawowe elementy składowe kultury strategicznej Niemiec:

- elementy fundacyjne, rozumiane jako centralne przekonania i wartości odnoszące się do zasad użycia siły, nadające kulturze strategicznej indywidualną specyfikę;

- wyznaczniki w polityce bezpieczeństwa, które należy rozumieć jako preferencje $\mathrm{w}$ polityce bezpieczeństwa stanowiące połączenia pośredniczące między elementami fundacyjnymi oraz praktykami regulacyjnymi;

- praktyki regulacyjne, jako praktyczne przejawy długoterminowej polityki, przenoszące treść kultury strategicznej na zewnątrz, dzięki którym nabiera ona znaczenia $\mathrm{i}$ jest stosowana w praktyce.

Składowe kultury strategicznej według K. Longhurst skorelowane zostały z poziomami analizy polityki zagranicznej państwa. Dzięki temu możliwe stało się szersze spojrzenie na kulturę strategiczną, w tym uniknięcie problemów interpretacyjnych pierwszej i drugiej generacji badań nad kulturą strategiczną ${ }^{15}$, ograniczających jej postrzeganie. Wybór trzech poziomów do analizy wyznaczników kultury strategicznej: międzynarodowego, państwowego i społecznego, zaczerpnięty z teorii badań nad polityką zagraniczną ${ }^{16}$, jest w dużej mierze zbieżny $\mathrm{z}$ analizą czynnikową źródeł kultury strategicznej. Potwierdzenie tego faktu odnaleźć można w publikacji V. Hudson, która dokonując analizy polityki zagranicznej na poziomie makro, przedstawiła podobne do źródeł kultury strategivcznej atrybuty systemu narodowego-państwowego i systemu międzynarodowego, stanowiące fundament dla obieranych kierunków działań państwa. ${ }^{17}$ Dlatego uznano, że analiza roli wyznaczników kultury strategicznej na różnych systemowych poziomach pozwoli na poszukiwanie w niej odniesień do ochrony środowiska.

W przedstawionej tabeli 2 analiza kultury strategicznej została rozszerzona o poziom społeczeństwa. Argumentem przemawiającym za takim ujęciem jest fakt, iż każdorazowo badacze kultury strategicznej odnoszą się do przekonań i wartości utrwalonych w danym społeczeństwie czy narodzie. Elity będące kreatorami i realizatorami kultury strategicznej nie tylko odwzorowują nastroje

${ }^{14}$ Longhurst K., Niemiecka kultura strategiczna, [w:] Kultura bezpieczeństwa narodowego $w$ Polsce i Niemczech, red. K. Malinowski, IZ, Poznań 2003, s. 193-218.

${ }^{15}$ Wiśniewski R., Kultura strategiczna, czyli o kulturowych uwarunkowaniach polityki zagranicznej i bezpieczeństwa, „Przegląd Strategiczny” 2012, nr 1, s. 168

${ }^{16}$ E. Haliżak, Poziomy analizy $w$ nauce o stosunkach międzynarodowych, s. 19-32 oraz W. Kostecki, Poziomy analizy w polityce zagranicznej, s. 113-127, oba [w:] Poziomy analizy stosunków międzynarodowych, red. E. Haliżak, M. Pietraś, tom I, Wyd. Rambler, Warszawa 2013.

${ }^{17}$ V. M. Hudson, The levels of National Attributes and International System, w: ta, Foreign Policy Analysis. Classic and Contemporary Theory, Second Edition, Rowman \& Littlefield 2014, s. $162-182$. 
Tabela 2: Poziomy uwarunkowań międzynarodowej aktywności państwa i jego kultury strategicznej

\begin{tabular}{|c|c|c|c|}
\hline $\begin{array}{l}\text { Poziomy analizy } \\
\text { / wyznaczniki }\end{array}$ & $\begin{array}{c}\text { System } \\
\text { międzynarodowy }\end{array}$ & $\begin{array}{c}\text { System } \\
\text { państwowy }\end{array}$ & Społeczeństwo \\
\hline $\begin{array}{l}\text { Elementy } \\
\text { fundacyjne }\end{array}$ & $\begin{array}{l}\text { - repertuar opcji } \\
\text { działania państwa } \\
\text { (np. przestrzeganie } \\
\text { norm i zasad } \\
\text { międzynarodowych) }\end{array}$ & $\begin{array}{l}\text { - przyjęte sposoby } \\
\text { realizacji interesów } \\
\text { narodowych (np. kwestia } \\
\text { użycia siły) } \\
\text { - priorytety polityki } \\
\text { bezpieczeństwa }\end{array}$ & $\begin{array}{l}\text { - historyczne } \\
\text { doświadczenia } \\
\text { - percepcja ról } \\
\text { - symbole } \\
\text { - tożsamość narodowa }\end{array}$ \\
\hline $\begin{array}{l}\text { Wyznaczniki } \\
\text { polityki } \\
\text { bezpieczeństwa }\end{array}$ & $\begin{array}{l}\text { - rola podmiotu } \\
\text { w bezpieczeństwie } \\
\text { międzynarodowym } \\
\text { (inicjowanie działań, } \\
\text { budowanie sojusz, } \\
\text { rozbrojenie-zbrojenie) }\end{array}$ & $\begin{array}{l}\text { - system instytucjonalny } \\
\text { - rola i organizacja sił } \\
\text { zbrojnych } \\
\text { - style rządzenia }\end{array}$ & $\begin{array}{l}\text { - aspiracje narodowe } \\
\text { - stosunek do użycia siły } \\
\text { - rola elit }\end{array}$ \\
\hline $\begin{array}{l}\text { Praktyki } \\
\text { regulacyjne }\end{array}$ & $\begin{array}{l}\text { - postrzeganie przez } \\
\text { partnerów i sąsiadów }\end{array}$ & $\begin{array}{l}\text { - kultura organizacyjna } \\
\text { - zarządzanie procesami } \\
\text { decyzyjnymi } \\
\text { - relacje cywilno-wojskowe }\end{array}$ & $\begin{array}{l}\text { - poziom zaangażowania } \\
\text { obywateli } \\
\text { - dyskurs nt. } \\
\text { bezpieczeństwa }\end{array}$ \\
\hline
\end{tabular}

Źródło: zestawienie własne na podstawie K. Longhurst, dz. cytowane.

społeczne, są także - w imieniu społeczeństwa - nośnikiem doświadczeń historycznych i budowanych w ich ramach utrwalonych wzorców. Zakładając za K. Malinowskim iż doświadczenia historyczne, których nośnikiem jest społeczeństwo i jego elity, stanowią o specyfice danej kultury strategicznej, należy uwzględnić je w rozważaniach o kulturze strategicznej, obok poziomu międzynarodowego i państwowego.

\section{WYZNACZNIKI KULTURY STRATEGICZNEJ NIEMIEC A OCHRONA ŚRODOWISKA}

Odnalezienie zagadnień ochrony środowiska w wyznacznikach kultury strategicznej Niemiec opierać się będzie na analizie czynników tworzących charakterystyczne dla tego państwa elementy fundacyjne, kwantyfikatory polityczne oraz praktyki regulacyjne. ${ }^{18}$

W ramach specyficznych dla Niemiec przekonań i kierunkowych wartości wpływających na kształt polityki zagranicznej i bezpieczeństwa znajdują się zagadnienia zarówno o charakterze moralno-historycznym, jak i organizacyjno-wojskowym. Zaliczana do pierwszej grupy kwestia wywołania i przegranej w drugiej wojnie światowej powoduje tzw. historyczne pęknięcie, czyli zakorzenione głęboko poczucie winy i źródło wstydu, które staje się motywem nie tyle

${ }^{18}$ za: K. Longhurst, dz. cytowane. 
przezwyciężenia przeszłości, co ucieczki przed nią. Warto zdać obie sprawę, że obserwowane w postawach społecznych współczesnych Niemiec zaangażowanie cywilne jest nie tylko wynikiem zorganizowanego kształcenia postaw obywatelskich po 1949 r. przez mocarstwa okupacyjne, ale ma także swoje fundamenty w naturalnym przekierowaniu aktywności społecznej na nowe, antymilitarne i niemilitarne obszary. ${ }^{19} \mathrm{~W}$ warstwie dyskursu przedstawia się ten moment jako Stunde Null (godzinę zero). Bezpośrednio łączy się ona z drugim charakterystycznym elementem fundacyjnym dla kultury strategicznej Niemiec - odrzuceniem siły jako narzędzia polityki. Realizacja interesów narodowych ma odbywać się poprzez zanegowanie rewizjonizmu i konfrontacji, a przede wszystkim polegać na dążeniu do stabilności i konsensusu. Motyw porozumienia, poszukiwania jednomyślności i kooperacji jest charakterystyczny w międzynarodowych działaniach na rzecz ochrony środowiska. Niemcy zaś uznawane są i chętnie same widzą się w roli moderatora, koordynatora i mediatora na polu czy to negocjacji klimatycznych, czy w ramach innych reżimów ochrony środowiska naturalnego. ${ }^{20}$ Choć pojawiają się głosy o generalnej nieskuteczności prowadzonej przez Berlin polityki dialogu ${ }^{21}$ to nie zmienia to faktu, że repertuar możliwych zmian zachowania tego państwa jest ograniczony ze względów historycznych oraz w kontekście powiązań międzynarodowych. Ograniczenie znaczenia spraw militarnych i zdystansowanie społeczeństwa wobec armii nie tylko przełożyło się na rozpowszechnienie różnych form służby cywilnej, ale, co bardziej istotne, przyczyniło się do rozkwitu postaw pacyfistycznych i proekologicznych. To w ich rozwoju upatrywać można w latach 60. XX wieku wykształcenia się oddolnego nurtu ,zielonej” reprezentacji społeczeństwa, opowiadającej się za odejściem od energetyki atomowej i za ochroną zasobów przyrodniczych. Nie bez znaczenia jest fakt wejścia w latach 80 . $\mathrm{XX}$ wieku partii Zielonych do Bundestagu ${ }^{22}$, a przez to partycypowania tego nurtu społeczno-politycznego w dyskursie publicznym o kierunkach działania państwa. Można zauważyć wykształcenie się w ciągu kilku dekad elit z rodowodem ruchu ekologicznego, którego czołowym przedstawicielem jest J. Fischer, były minister spraw zagranicznych. Zachwianie po drugiej wojnie światowej lojalności wobec państwa narodowego i odrzucenie Realpolitik wzmocniło koncepcję małych ojczyzn i dążenie do zakotwiczenia RFN w strukturach międzynarodowych. W wymiarze międzynarodowym multilateralizm stał się miarą działań państwa

${ }^{19}$ Szerzej w rozdziale Umweltbewegungen vor der Umweltbewegung autorstwa J. Radkau, [w:] tenże, Die Ära der Ökologie, BpB, Bonn 2011, s. 58-124.

${ }^{20}$ Widner H., Klimaschutzpolitik: Warum ist Deutschland ein Vorreiter im internationalen Vergleich? Zur Rolle von Handlungskapazitäten und Pfadabhängigkeit, Discussion Paper SP IV 2008-303, Wissenschaftszentrum Berlin für Sozialforschung, Berlin 2008.

${ }^{21}$ M. Kędzierski, Niemcy - wiarygodny sojusznik? Wywiad z Justyna Gotkowska, http:// www.nowapolitologia.pl/politologia/stosunki-miedzynarodowe/niemcy-wiarygodny-sojusznik-wywiad-z-justyna-gotkowska, 11 marca 2015 [10.12.2015].

${ }^{22}$ Szerzej: Kleinert H., Vom Protest zur Regierungspartei: die Geschichte der Grünen, Frankfurt am Main 1992. 
i jego struktur. Legitymizował on wszelkie działania Niemiec na arenie międzynarodowej i do dziś pozostaje bardzo ważnym motywem kultury strategicznej.

Reasumując ocenę wartości fundacyjnych warto wskazać ich obecność w warstwie dyskursu. Metafory ${ }^{23}$, „Nie wieder Krieg” jako imperatyw unikania wojny i agresji, „Nie wieder Alleingang” jako świadoma rezygnacja z unilateralnych zachowań na arenie międzynarodowej, „Nie wieder Sonderweg” jako unikanie wejścia na drogę specyficzną tylko dla Niemiec i wzmacnianie instytucji bezpieczeństwa międzynarodowego, oraz „Selbsteinbindung” jako dążenie do samozakotwiczania się w ramach multilateralizmu, stały się wyznacznikami kształtowania kultury strategicznej Niemiec i w pełni współgrają z otwartością w podejmowaniu tematyki globalnych zagrożeń ekologicznych i multilateralnemu rozwiązywaniu problemów ochrony środowiska.

Druga grupa wyznaczników obejmująca przede wszystkim preferencje w polityce bezpieczeństwa każe poszukiwać odniesień do ochrony środowiska i bezpieczeństwa ekologicznego w promowaniu stabilności w sferze bezpieczeństwa. Podkreślanie szerzej roli sił zbrojnych i dążenie do ich integrowania z pozawojskowymi dziedzinami polityki wprost przełożyć można na zaangażowanie Bundeswehry w udzielanie pomocy humanitarnej i większy udział w misjach cywilnych niż wojskowych.

Skłonność do realizacji własnych interesów poprzez rozwiązania wielostronne budzi jednakże zasadnicze pytanie o możliwość instrumentalnego traktowania multilateralizmu. Może być bowiem postrzegany jako strategia maksymalizowania własnych wpływów, w ramach której dokonuje się racjonalnej kalkulacji kosztów i zysków w imię budowy zaufania wobec Niemiec. Z drugiej strony niezaprzeczalne jest istnienie w kulturze strategicznej tego państwa nawyku działania $\mathrm{w}$ ramach wielostronnych, współpracy z partnerami w ramach instytucji międzynarodowych, jak też przyjęcia przez elity decyzyjne zinternacjonalizowanych norm zachowań. W ramach tak dualistycznie pojmowanego multilateralizmu powstaje pytanie czy idea ochrony środowiska jako dobra wspólnego, konstytuującego rozwój i przetrwanie, jest jedynie retoryczną nadbudową dla realistycznej polityki RFN, dążącej do realizacji własnych, partykularnych celów narodowych?

Istotnym markerem wyznaczników politycznych jest kwestia oczekiwań ze strony sojuszników oraz własnych aspiracji do odpowiedzialności za bezpieczeństwo międzynarodowe. Z pewnością ważną rolę w tym zakresie odgrywają działania Niemiec zorientowane nie tylko na zapewnienie sobie stałego członkostwa w Radzie Bezpieczeństwa ONZ, ale także akcentowanie w jej ramach tematyki bezpieczeństwa ekologicznego. Dużą rangę należy także nadać przywództwu politycznemu i czynnikowi jednostkowemu. Silna pozycja kanclerz A. Merkel, która jak przystało na byłą minister ds. środowiska, należy do niekwestionowanych politycznych liderów reagowania na zmiany klimatyczne, pozwala Niemcom

${ }^{23}$ Malinowski K., Przemiany niemieckiej polityki bezpieczeństwa 1990-2005, Instytut Zachodni, Poznań 2005, s. 485. 
inicjować międzynarodowe koalicje i porozumienia. Determinacja w budowaniu konsensusu na poziomie decyzyjnym w sferze stosunków międzypaństwowych i na poziomie wewnętrznym (federalnym) pogłębia tylko postrzeganie Niemiec jako partnera odpowiedzialnego, przewidywalnego i godnego zaufania.

Na poziomie praktyk regulacyjnych, które według K. Longhurst przenoszą treść kultury strategicznej na zewnątrz i przez to nadają jej określone znaczenie i umożliwiają zastosowanie, wyróżnić można założenia rządzące i środki normatywne. Odnoszą się one do zakotwiczenia struktur wojskowych Niemiec w organizacjach zbiorowego bezpieczeństwa, normatywne określenie zadań dla sił zbrojnych, jak też kontrolę cywilną nad środkami wojskowymi. W tych ramach zagadnienia ochrony środowiska przejawiają się w dyskursie na temat koncepcji mocarstwa cywilnego (Zivilmacht) oraz koncepcji rozszerzonego bezpieczeństwa (vernetzte Sicherheit).

Pierwsza z nich ${ }^{24}$, uwypuklając cywilne aspekty polityki zagranicznej państwa niemieckiego, realizuje się na wielu płaszczyznach międzynarodowej działalności i cechuje się rozwijaniem współpracy i integracji oraz multilateralizmem i poszanowaniem dla norm międzynarodowych. W tych ramach płaszczyzna ochrony środowiska nie stanowi podstaw do rywalizacji z innymi podmiotami. Wizerunek Niemiec budowany jest jako wizerunek państwa wzoru, nadającego ton w zakresie rozwijania technologii sprzyjających ochronie klimatu i środowiska, troszczącego się o ochronę zasobów naturalnych jako podstaw egzystencji. Mocarstwo cywilne rościć będzie sobie prawo do kreowania stosunków międzynarodowych, silnie podkreślać prymat prawa, aktywnie uczestniczyć na forum organizacji międzynarodowych, nie wykluczać lecz ostrożnie podchodzić do kwestii użycia siły w stosunkach międzynarodowych, dążyć do cywilizowania stosunków poprzez kooperację, prowadzić politykę wiarygodną i obliczalną, przestrzegać normy oraz unikać przemocy i nacisku. ${ }^{25}$ Poprzez zaangażowanie w politykę rozwojową, pomoc humanitarną i przeciwdziałanie zmianom klimatycznym RFN poszerza sferę swych wpływów do skali ogólnoświatowej jako tzw. mocarstwo cywilne.

W koncepcji rozszerzonego bezpieczeństwa (Vernetzte Sicherheit), wyrażonej w Białej Księdze z 2006 r. ${ }^{26}$, wskazuje się, że ,,w pierwszej linii nie militarne, lecz społeczne, ekonomiczne, ekologiczne i kulturalne uwarunkowania określaja przyszłe kierunki rozwoju polityki bezpieczeństwa, wptywać na nie można tylko poprzez międzynarodowa wspótprace, $w$ strukturach powiazanych ze soba oraz poprzez świadomość konieczności budowy globalnej tożsamości bezpieczeństwa”. Podejście takie oznacza stosowanie instrumentów cywilnych na równi z instrumentami wojskowymi, zwłaszcza rozwijanie w ramach działań zewnętrznych projektów

${ }^{24}$ Harnisch S., Teoria ról i Niemcy jako państwo cywilne. Rozważania teoretyczne nad zmiana niemieckiej polityki zagranicznej 1990-2005, [w:] Niemcy jako państwo cywilne. Studia nad niemiecka polityka zagraniczna, red. K. Bachmann, P. Buras, Wyd. ATUT, Wrocław 2006, s. 19-68.

${ }^{25}$ Za: Geroudet A., Mocarstwo cywilne Niemcy?, „Niemcoznwstwo” 2007, nr 15, s. 177.

${ }^{26}$ Weißbuch 2006 zur Sicherheitspolitik Deutschlands und zur Zukunft der Bundeswehr, Bundesministerium der Verteidigung, Berlin, Oktober 2006. 
szkoleniowych, budowania pokoju i stabilności, pomocy rozwojowej i gospodarczej, wspieranie demokratyzacji i praw człowieka, zrównoważonego rozwoju.

Wykorzystanie tej koncepcji do działań prośrodowiskowych w obszarze bezpieczeństwa jest niekwestionowane. Szeroko pojmowana ochrona środowiska i zasobów naturalnych staje się instrumentem przeciwdziałania zagrożeniom. Metafora „Klimaschutz ist präventive Sicherheitspolitik“ - ochrona klimatu jako prewencyjna polityka bezpieczeństwa w pełni oddaje istotę wykorzystania zagadnień ekologicznych w strategii państwa. Ponadto Energiesicherheitspolitik w polityce bezpieczeństwa rozumiana jest jako przejaw zabezpieczenia stabilnego wzrostu społeczno-gospodarczego w związku z kurczącymi się zasobami, zaś Entwicklungspolitik (polityka rozwojowa) jako forma redukcji ryzyka eskalacji konfliktów na tle ekologicznym.

\section{POZIOMY ANALIZY ŹRÓDEŁ KULTURY STRATEGICZNEJ NIEMIEC A OCHRONA ŚRODOWISKA}

Zdaniem K. Malinowskiego podstawowymi elementami składającymi się na system myślenia strategicznego o miejscu danego państwa w systemie międzynarodowym są narodowe doświadczenie historyczne i zakorzeniony na ich bazie system norm i praktyk. Przejawiające się w zachowaniach państwa dyspozycje są wynikiem istnienia struktur interpretacyjnych tkwiących głęboko w świadomości społecznej. To one modelują artykulację interesów narodowych przez elity polityczne, działające w ramach ukształtowanej dyspozycjami kulturze bezpieczeństwa. ${ }^{27}$ Horyzontalna i wertykalna analiza źródeł kultury strategicznej Niemiec pozwala więc wyznaczyć obszary jej fundamentalnych uwarunkowań, w ramach których poszukiwano odniesień do zagadnień ochrony środowiska.

Na poziomie systemu międzynarodowego czynnikiem spajającym wyznaczniki kultury strategicznej Niemiec są procesy internacjonalizacji problemów ekologicznych. Współzależność państw, wzajemne oddziaływania na siebie podmiotów w ramach multilateralnych oraz proces globalizacji przyczyniają się do udziału Niemiec w reżimach ochrony środowiska na poziomie ogólnoświatowym i regionalnym. Berlin jest aktywnym podmiotem budowy bezpieczeństwa międzynarodowego jako podstawy dalszego rozwoju. W tym zakresie inicjuje działania w ramach organizacji międzynarodowych, np. w ramach Rady Bezpieczeństwa ONZ w 2011 i 2014 r. podejmował tematykę bezpieczeństwa państw wyspiarskich $^{28}$, w Unii Europejskiej był inicjatorem pakietu klimatyczno-energetycznego

${ }^{27}$ Malinowski K., Polska kultura strategiczna: historyczne reminiscencje i polityczne realia, [w:] Kluczowe determinanty bezpieczeństwa Polski na poczatku XXI wieku, red. S. Wojciechowski, A. Wejkszner, Wyd. Difin, Warszawa 2013, s. 33.

${ }^{28}$ Grußwort von Außenminister Frank-Walter Steinmeier beim deutschen Empfang anlässlich des VN-Klimagipfels, 24.09.2014, http://www.auswaertiges-amt.de/DE/Infoservice/Presse/Reden/2014 /140924-BM_Dt_Empfang_Klimagipfel.html [15.12.2015]. 
3x20\%, zaś w ramach Grupy G7 przeforsował deklarację redukcji emisji i dekarbonizacji najpotężniejszych gospodarek świata. ${ }^{29} \mathrm{~W}$ Bonn znajdują się siedziby kluczowych obecnie instytucji w ramach globalnej dyskusji o konsekwencjach zmian klimatycznych: zarówno siedziba sekretariatu Ramowej Konwencji ds. zmian klimatu, jak też Centrum Innowacji i Technologii Międzynarodowej Agencji ds. Energetyki Odnawialnej (IRENA). Niemcy postrzegane są przez partnerów jako państwo pełniące rolę innowatora i lidera w zakresie ochrony środowiska.

Na poziomie systemu państwowego warto podkreślić rolę konsensualnego modelu prowadzenia dyskusji i włączania do procesu strategicznego planowania wielu podmiotów zajmujących się kwestiami środowiska. Działania te mają charakter procesów zarówno formalnych, jak i nieformalnych, nad którymi czuwa rozbudowany aparat biurokratyczny osadzony w ministerstwach, na czele z Urzędem Kanclerskim. Rozbudowany system instytucjonalny w zakresie środowiskowego doradztwa politycznego (Umweltrat i Wissenschafliche Beirat der Bundesregierung Globale Umweltveränderungen), konieczność wypracowywania porozumień na szczeblu krajów związkowych w ramach systemu federalnego tworzą skomplikowany układ zależności. Potencjał gospodarczy Niemiec sprzyja strategicznemu myśleniu o zabezpieczeniu dróg eksportu i promocji innowacji technologicznych w zakresie ochrony środowiska.

$\mathrm{Na}$ poziomie społecznym społeczna kontrola procesów politycznych oraz daleko idąca partycypacja obywatelska i zaangażowanie w organizacjach pozarządowych sprzyjają zakotwiczaniu zagadnień środowiskowych w bieżącej działalności państwa i strategicznym planowaniu jego rozwoju. Procesy te wspomagane są przez rozwinięte studia środowiskowe i technologiczne, kształcące kadry na stanowiska federalne, pełniące funkcje tzw. knowledge brokers. Opinia publiczna staje się ważnym nośnikiem nastrojów w zakresie optyki zmian klimatu i dekarbonizacji gospodarki, ale także wyznacznikiem bieżących ról i aspiracji narodowych, jakie Niemcy powinni odgrywać na świecie i w regionie.

\section{WNIOSKI}

W dyskusji o kulturze strategicznej i sile Niemiec na arenie międzynarodowej pojawiają się głosy o próbie budowy nowej, dominującej pozycji niemiec$\operatorname{kiej}^{30}$, ale także przeciwne, wskazujące na brak strategicznej bazy i orientacji w polityce bezpieczeństwa. ${ }^{31}$ Jednakże J. Junk i Ch. Daase wyjaśniają, że nie tyle

${ }^{29}$ G7-Präsidentschaft 2015: Abschlussbericht der Bundesregierung über die G7-Präsidentschaft 2015, http://www.auswaertiges-amt.de/cae/servlet/contentblob/724292/publicationFile/212782/160202-G7_Praes_Abschlussbericht.pdf [15.12.2015].

${ }^{30}$ Koszel B., Mocarstwowe aspiracje Niemiec w Europie XXI wieku: realia i perspektywy (Raport z badań), IZ Policy Papers, nr 6 (I), Iznstytut Zachodni, Poznań 2012.

${ }^{31}$ Maull H. W., Deutsche Außenpolitik: Orientierungslos, "Zeitschrift für Politikwissenschaft" 2011, t. 21, nr 1, s. 93-117. 
w ostatnich latach chodzi o brak strategicznej orientacji, co bardziej o problem w adaptacji własnej, ukształtowanej historycznie architektury bezpieczeństwa do nowych, szeroko rozumianych wyzwań. ${ }^{32}$ Warto wszakże dodać, że Niemcy nie posiadają jasno określonej strategii własnego bezpieczeństwa. Brak strategicznego dokumentu, który „definiowałby interesy narodowe, cele strategiczne, wyzwania i zagrożenia dla bezpieczeństwa RFN oraz sposoby przeciwdziałania im" ${ }^{\prime 3}$ powoduje, że nie istnieją wyznaczniki działań dla instytucji federalnych i landowych, nie ma także jasnego przekazu skierowanego do własnego społeczeństwa i sojuszników. ${ }^{34}$

Poszukując odpowiedzi na pytanie czy i dlaczego zagadnienia ochrony środowiska pojawiają się w kulturze strategicznej Niemiec można odnieść do kwestii czy i na ile kultura strategiczna się zmienia. ${ }^{35}$ Dotychczasowe studia dotyczące kultury strategicznej w żaden sposób nie włączały kwestii środowiska do rozważań. Oczekiwanie, że kultura strategiczna jest stała w badanym okresie czasu ma walor analityczny, lecz należy uwzględnić, że może podlegać zmianom w następstwie sytuacji kryzysowych, wojen, znaczących zmian w środowisku międzynarodowym, a także ewolucji norm, wzorców zachowań będących ich następstwem. Kulturowo uwarunkowana zmiana dyspozycji może stać się przyczyną reinterpretacji lub dyskusji nad redefinicją interesu narodowego i obowiązujących dotąd zasad. Taka sytuacja ma miejsce w przypadku Niemiec. Refleksja dotycząca strategicznego działania tego państwa ${ }^{36}$ potwierdza hipotezy autorki o ugruntowywaniu się kwestii ochrony środowiska w myśleniu strategicznym, ale także swego rodzaju kontynuacji dotychczasowych działań. Dotyczy to zarówno procesu ekologizacji polityki zagranicznej i bezpieczeństwa Niemiec, jak też postrzegania zmian klimatycznych i nieograniczonej eksploatacji zasobów nieodnawialnych jako zagrożeń dla bezpieczeństwa oraz pokojowej egzystencji i rozwoju. Nowa tendencją jest wskazanie na konieczność większego zaangażowania Niemiec w zabezpieczanie globalnego przepływu usług i towarów, potrzeba rozwinięcia nowej narracji w polityce bezpieczeństwa, która dotyczyłaby ochrony tzw. globalnych dóbr wspólnych (global commons), zastępowanie niemieckiej powściągliwości przez „przejmowanie odpowiedzialności”, wzmacnianie przywództwa w zakresie globalnej polityki zmian klimatu, rozwijanie instrumentarium

32 Junk J., Daase Ch., Germany, [w:] Strategic Cultures in Europe. Security and Defence Policies Across the Continent, Eds: Biehl H., Giegerich B., Jonas A., Schriftenreihe des Zentrums für Militärgeschichte und Sozialwissenschaften der Bundeswehr, Volume 13, Springer VS, Wiesbaden 2013, s. 139.

${ }^{33}$ Gotkowska J., W polowie drogi do petnoletności - niemiecka polityka bezpieczeństwa. Między presja sojuszników i ambicjami politycznymi a brakiem strategii i sceptycyzmem spoteczeństwa, „Biuletyn Niemiecki”, CSM, Warszawa,10.03.2010, nr 4, s. 5.

${ }^{34}$ Tamże.

${ }^{35}$ Biehl H., Giegerich B., Jonas A., dz. cytowane, s. 13.

${ }^{36}$ Review 2014 - Aussenpolitik weiter denken, http://www.aussenpolitik-weiter-denken.de/ de/themen.html [15.12.2015]. 
prewencyjnego i z zakresu zarządzania kryzysami, opartych o komponenty cywilne i wojskowe, wzmacnianie obecności politycznej i wojskowej w regionach konfliktów, jednakże wsparcie udzielne przez Bundeswehrę powinno koncentrować się na transporcie, logistyce, służbie medycznej, szkoleniach wojskowych, dostarczaniu broni. W tym zakresie nie ma większej dychotomii między elitami a opinią publiczną, co tylko może wzmocnić proces ciągłości wdrażania zasad multilateralizmu jako środka zapewniania bezpieczeństwa. ${ }^{37}$ Potwierdza również oddziaływanie i obecność ochrony środowiska w konstruowaniu dyspozycji państwa w ramach kultury strategicznej.

\title{
ENVIRONMENT PROTECTION IN GERMAN'S STRATEGIC CULTURE
}

\begin{abstract}
The purpose of the article is analysis of a role of environmental protection in strategic culture of Germany with particular taking into consideration protection of climate. Inclusion of question of environmental protection in to research of determinants of state's foreign and security policy is indirect purpose of the article. The case of Germany is particular in this situation. This state on the one hand has no strategy of national security, but on the other hand aspirates to play significant role in both international security policy and international environmental protection including protection of climate. I the article has been joint general knowledge about environmental protection and strategic cultures with detailed knowledge about models of analyses of Germany's strategic culture with determinants of Germany's strategic culture including environmental protection, and levels of analyses of strategic culture of that states.
\end{abstract}

Key words: environment protection, strategic culture, Germany

${ }^{37}$ Czaja J., Kulturowe czynniki bezpieczeństwa, Oficyna Wyd. AFM, Kraków 2008, s. 255-264. 